\title{
Growth data and tumour risk of 32 Chinese children and adolescents with 45,X/46,XY mosaicism
}

Lili Pan, Zhe Su* ${ }^{*}$, Jianming Song, Wanhua Xu, Xia Liu, Longjiang Zhang, Shoulin Li and on behalf of the multidisciplinary collaboration team of DSD management at Shenzhen Children's Hospital

\begin{abstract}
Background: The aim of this study was to review the growth data, gonadal function and tumour risk of children and adolescents with 45,X/46,XY mosaicism who presented to a single centre in China.

Methods: We conducted a retrospective review of the records of 32 patients with 45,X/46,XY mosaicism or variants who were hospitalized from August 2005 to September 2018. The main outcomes measured were growth data, genital phenotype, gonadal function, gonadal position, and histological results.

Results: A total of 32 patients were included. The age at diagnosis ranged from 0.6 to 16.3 years. Nineteen patients exhibited ambiguous genitalia, 12 had short stature, and 1 showed a lack of breast development. Seventeen patients were raised as males, and 15 were raised as females. The external masculinisation score (EMS) of patients raised as male was 4.5 (1 12) [median (range)]. The EMS of the females was 0 (0 1.5) [median (range)]. Patients showed normal heights under 2 years old, with a height SDS of $0(-1.5 \sim 1.4)$ [median (range)]. Growth appeared to decelerate after age 2 years, with SDS decreased to $-2.8(-3.0 \sim-0.9)$ [median (range)]. The percentage of short stature was higher in females than in males (76.9\% vs 50.0\%). Twenty-five patients had gonadal pathological results. Complete gonadal dysgenesis (CGD) and mixed gonadal dysgenesis (MGD) were the most common pathogenic subtypes, accounting for 48.0 and $36.0 \%$, respectively. Ovotesticular tissue was observed in only $4.0 \%$ of patients. Gonadoblastoma and positive OCT3/4 results were found in $18.8 \%$ of gonads in children over 2 years of age. Palpable gonads accounted for $50 \%$ of these. All patients who had gonadoblastoma were raised as females.
\end{abstract}

Conclusions: Patients with 45,X/46,XY might have normal heights until 2 years old.

Growth decelerations after 2 years of age were common. Patients who are being raised as females seemed to be shorter than males. CGD and MGD were the most common gonadal pathogenic subtypes. The tumour risk is high in these patients, even in palpable gonads and female patients.

Keywords: 45,X/46,XY mosaicism, Growth, Gonadoblastoma, Gonadal dysgenesis

\section{Background}

The $45, \mathrm{X} / 46, \mathrm{XY}$ disorders of sex development (DSD) is a rare congenital malformation $[1,2]$. It occurs with an estimated incidence of 1 per 10,000 individuals [3]. Only approximately 10 papers have focused on children and adolescent patients. There have been limited reports of 45,X/46, XY mosaicism from China, and few of these include follow-up data on the patients' heights or the

\footnotetext{
* Correspondence: Su_zhe@126.com

Director of Endocrinology department, Shenzhen Children's Hospital, No. 7019,

Yitian Road, Shenzhen 518038, Guangdong Province, People's Republic of China
}

risk factors for gonadoblastoma. In the current study, we identified 32 children and adolescents with 45,X/46,XY mosaicism and reported their growth data, genital phenotypes, gonad function evaluation, gonadal position and histological results, as well as a review of the literature.

\section{Methods \\ Patients}

In this retrospective analysis, we identified all patients with $45, \mathrm{X} / 46, \mathrm{XY}$ mosaicism who were hospitalized in Shenzhen Children's Hospital from August 2005 to

(C) The Author(s). 2019 Open Access This article is distributed under the terms of the Creative Commons Attribution 4.0 International License (http://creativecommons.org/licenses/by/4.0/), which permits unrestricted use, distribution, and 
September 2018. We also included patients who showed aberration of the Y-chromosome. We evaluated 44 patient record files, of which 12 had incomplete information and were eliminated. A final group of 32 consecutive patients were included in the study.

\section{Karyotyping}

Blood sample (0.3-0.5 ml, heparin anticoagulation) was added into cell culture medium (Dubai Biomedical Co. Ltd., Guangzhou, China). Dolchicine was added into the culture medium at $69 \mathrm{~h}$. Culture was carried out for 72 h. Karyotyping were performed on cultured blood lympthocytes arrested in the mitosis phase and stained with Giemsa dye. Thirty to 100 mitoses were examined to determine the percentage of cell line mosaicism. All karyotypes were evaluated by an experienced clinical geneticist, and according ISCN 2016 [4].

\section{Clinical examinations}

Patients' heights were measured on a wall-mounted stadiometer. Height evaluation was calculated as described by $\mathrm{Hu}$ et al. [5], and is expressed as age- and sex-specific standard deviatibon scores (SDSs). Pubertal staging was performed according to the criteria of Tanner [6,7]. Testicular volume was measured using a Prader orchidometer. Spontaneous pubertal onset was defined as testicular volume $\geq 4 \mathrm{ml}$ for males or the appearance of breast stage 2 for females without sexual hormone replacement. All patients were scored using the external masculinisation score (EMS) as described by Ahmed et al. [8]. The hypothalamic-pituitary-gonadal (HPG) axis function was evaluated by basal sexual hormone examination, gonadotropin releasing hormone $(\mathrm{GnRH})$ stimulating assay (injectable gonadorelin $2.5-3.0 \mu \mathrm{g} / \mathrm{kg}$ and no more than $100 \mu \mathrm{g}$ at a time), and human chorionic gonadotrophin hCG stimulation test (a single dose of hCG injection at a dose of $500 \mathrm{IU} /$ Day, $1000 \mathrm{IU} /$ Day and $1500 \mathrm{IU} /$ day $\times 3$ or every other day $\times 3$ for patients younger than 1 year old, between 1 to 10 years old and older than 10 years, respectively). Hypergonadotropic hypogonadism was defined as basal follicle stimulating hormone (FSH) greater than or equal to $40 \mathrm{IU} / \mathrm{L}$ [9].

\section{Surgery and histology}

Before surgery, decisions were considered by a multidisciplinary team, including endocrinologists, urologists, gynaecologists, psychologists, pathologists, and ethics committees, and were discussed with the family at all stages of this process.

Gonad tissue samples were fixed in buffered formalin. Histological examinations were performed on haematoxylineosin-stained sections. Complete gonadal dysgenesis (CGD) was defined as bilateral streak gonads. Partial gonadal dysgenesis (PGD) was defined as dysplastic testes.
Mixed gonadal dysgenesis (MGD) was defined as a streak gonad on one and a contralateral testis. Ovotesticular tissue (OT) was defined as the combined presence of testis and ovarian tissue in the same individual [10].

Immunohistochemical evaluation with antibodies against octamer binding transcription factor 3/4 (OCT3/4) [11] was performed in all gonadal tissues, using the following antibody anti-OCT3/4 (MAB-0618, Fuzhou Maixin Biotech. Co. Ltd., China). A standard indirect peroxidase method with reagents and secondary antibodies from the Ultra-view Universal Diaminobenzidine (DAB) kit (Dako, Denmark) was provided by Roche. DAB was used as chromogen in the peroxidase staining for OCT3/4. Positive results were evidenced by brown staining. The positive control was sample from germinoma which is known as OCT3/4 positive. The negative control used the patient sample with a primary antibody replaced by Phosphate Buffered Saline (PBS).The description of the gonadal pathology and tumours was performed according to WHO Classification of Tumours of the Urinary System and Male Genital organs [12].

\section{Literature review and search strategy}

We searched two databases, PubMed and China National Knowledge Infrastructure (CNKI), for articles published from January 1988 to September 2018 using the following keyword: 45,X/46,XY mosaicism, growth and gonadal dysgenesis. Reports with more than 7 cases were included.

\section{Results}

Karyotypes of all the patients were $45, \mathrm{X} / 46, \mathrm{XY}$. However, three of them (No. 3, 5 and 21) had variants of the 45,X/46,XY karyotype: 45,X/46,XY/46,X,i(Y)(q10), 45,X/ $47, \mathrm{XYY}$ and $45, \mathrm{X} / 47, \mathrm{XXY}$.

The ages at diagnosis ranged from 0.6 to 16.3 years. The patients came with the following main complains: 19 presented with ambiguous genitalia, 12 exhibited short statures and 1 showed lack of breast development at age 14.3 years. Among the 32 patients, 17 patients were raised as males and 15 were raised as females. The EMS of patients raised as male was $4.5(1 \sim 12)$ [median (range)]. The EMS of the females was $0(0 \sim 1.5)$ [median (range)]. Seven out of 13 patients were consistent with the phenotypical features of Turner syndrome, such as widely spaced nipples and hypoplastic nails. Five patients $(5 / 32,15.6 \%)$ had congenital abnormalities, including horseshoe kidneys, ventricular septal defect, and duplex kidney. One patient had neural hearing loss and the phenotypical features of Turner syndrome.

\section{Growth data}

In our study, there were 27 patients with records of height. Heights measured before 2 years of age $(n=7)$ were all 
within normal range, with a height SDS of 0 (-1.5 1.4) [median (range)]. Heights measured after 2 years of age $(n=27)$ were much shorter than normal, with a height SDS of $-2.6(-6.0 \sim 0.5) \quad$ [median (range)]. Among those 27 patients, 17 presented short stature (less than - 2.0 SDS). The percentage of short stature was higher but not significantly in females than in males [76.9\% (10/13) vs $50.0 \%(7 / 14), P=0.2943]$. The shortest patient in our study was a 14.8-year-old girl whose height was -6.0 SDS (Fig. 1). Interestingly, follow-up of those 7 patients who had height records before 2 years of age revealed growth deceleration after the age of 2 years. The height SDS decreased to $-2.8(-3.0 \sim-0.9)$ [median (range)] (Fig. 1). The changes in height SDS were $-1.5(-0.7 \sim-4.2)$ [median (range)].

\section{Pubertal development and HPG axis evaluation}

Two out of 32 patients (No. 1 and 27) had spontaneous pubertal development with testicular volumes of $8 \mathrm{ml}$ at age 12.4 years and $6 \mathrm{ml}$ at age 15.2 years, and the EMSs were 4.5 and 12, respectively. Their LH levels increased from $4.66 \mathrm{IU} / \mathrm{L}$ to $51.37 \mathrm{IU} / \mathrm{L}$ and from $2.18 \mathrm{IU} / \mathrm{L}$ to 33.92 $\mathrm{U} / \mathrm{L}$, and their FSH levels increased from $14.53 \mathrm{IU} / \mathrm{L}$ to $30.48 \mathrm{IU} / \mathrm{L}$ and from $6.97 \mathrm{IU} / \mathrm{L}$ to $17.31 \mathrm{IU} / \mathrm{L}$ on the GnRH stimulating test, respectively.

The other nine patients (9/24) (No. 13, 14, 15, 19, 20, $22,29,24$ and 31) met the diagnosis of hypergonadotropic hypogonadism according to basal FSH levels, except for No. 24 and No. 31, whose basal FSH levels were $33.61 \mathrm{IU} / \mathrm{L}$ and $35.71 \mathrm{IU} / \mathrm{L}$ at the age of 3.5 and 4.0 years, respectively. The gonadal pathologies of those two patients were CGD.
GnRH stimulation tests were performed in 13 other patients. Their peak LH were all more than 1 IU/L. HCG stimulation tests were performed in twelve out of those 13 patients. Seven patients showed an increase in serum testosterone to more than $1 \mathrm{ng} / \mathrm{ml}$ (No. 6, 10, 11, 17, 21, 25 and 26), while 5 patients (No. 4, 8, 12, 30 and 32) failed to increase. The median EMSs of the groups of patients were 4.5 and 1.25 , respectively.

\section{Surgery and histological findings}

Twenty-five patients underwent gonadal biopsy, and 13 out of 25 patients underwent bilateral gonadectomy. Two male patients (No. 8 and 9) underwent bilateral gonadectomy at 2.7 and 1.4 years, and another 11 female patients underwent bilateral gonadectomy (No. 13, 14, 15, 16, 19, $20,24,28,29,31$ and 32 ) at the ages of 16.5, 11.4,14.5, $10.3,16.2,12.0,3.6,3.3,4.0$ and 8.0 years, respectively.

Thirty out of 32 patients were assigned to their previous gender, 2 patients (No. 8 and 9) underwent gender change from male to female at the ages of 2.7 and 1.6 years.

The gonadal pathogenic results were related to gonad positions. For 16 palpable gonads, (14/16) were dysgenetic testis, whereas $91.2 \%$ (31/34) of impalpable gonads were streak gonads. CGD and MGD were the most common gonadal pathogenic subtypes in our study. Twelve patients $(12 / 25,48 \%)$ presented CGD, all of whom were raised as females. Nine patients $(9 / 25,36 \%)$ showed MGD, seven of whom were raised as males and 2 as females. Three male patients $(3 / 25,12 \%)$ presented with PGD. One female patient $(1 / 25,4 \%)$ showed OT.

Overall, three out of 25 patients (No. 24, 28 and 32) had gonadoblastoma in 3 gonads. Diagnoses were made at the
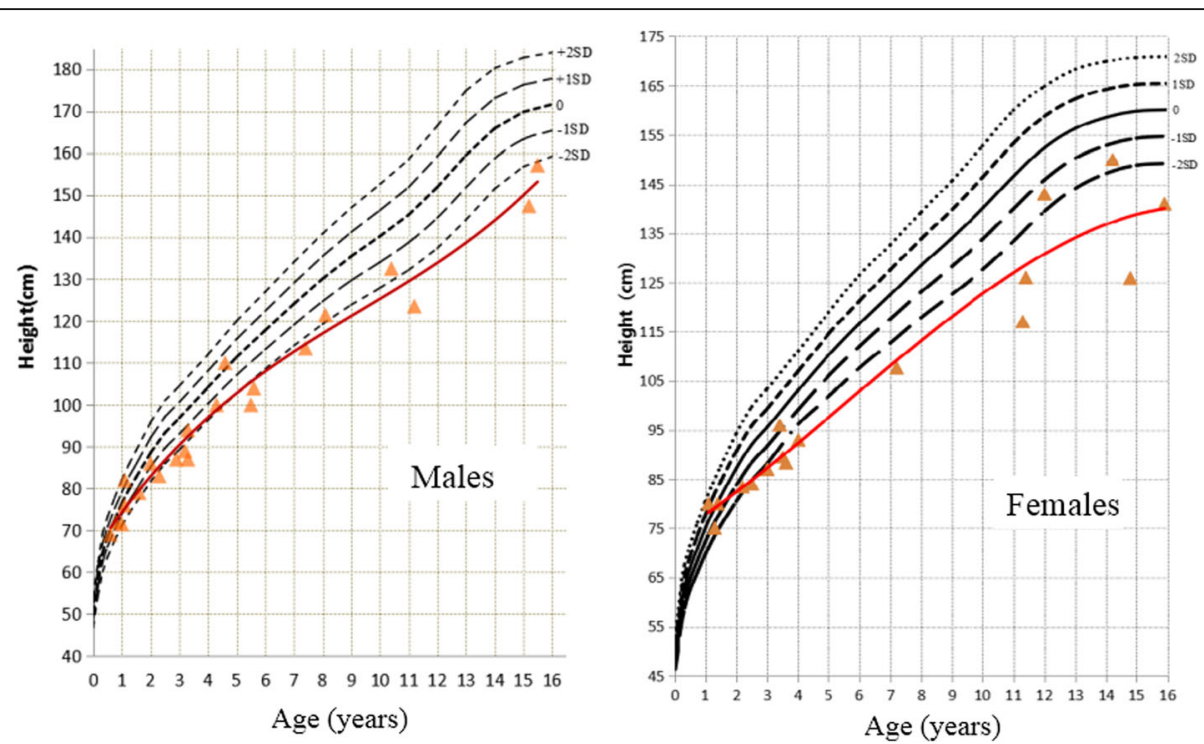

Fig. 1 Heights of patients. Heights were within the normal range in 7 patients who were measured before 2 years of age. Those patients revealed growth deceleration after the age of 2 years. Seventeen out of 27 patients (17/27) who were older than 2 years presented short stature (less than -2 SDS). The percentage of patients with short stature was higher in females than in males 
ages of 3.5, 3.3 and 8.0 years. The percentage of patients with gonadoblastoma reached $27.3 \%$ (3/11) of the female phenotype (EMS $=0$ ). Two patients (No. 2 and 18) with 3 gonads had positive reactions for OCT3/4 at the ages of 4.6 and 11.3 years, respectively. Gonadoblastoma and positive OCT3/4 results were found in $18.8 \%$ (6/32) of gonads in children over 2 years of age. Those positive results encompassed 6 gonads, with the locations being in the scrotal fold (2/6), inguinal region (1/6) and intra-abdominal region (3/6). Palpable gonads accounted for $50 \%$ of them.

Immunohistochemistry results and gonadoblastoma images are shown in Fig. 2 and Fig. 3, respectively.

\section{Literature search results}

We included 17 articles, of which 15 were written in English and 2 in Chinese; at the same time, we also read the review article by Colindres [13]. The characteristics of included studies are summarized in Table 1.

\section{Discussion}

The possible mechanism of $45, \mathrm{X} / 46, \mathrm{XY}$ mosaicism is thought to be the loss of non-disjunction of the Y chromosome after normal disomic fertilization [14]. 45,X/46,XY mosaicism can present with a wide spectrum of phenotypes in different age groups. Chang et al. suggest that $95 \%$ of $\mathrm{X} / \mathrm{XY}$ fetuses will have normal male genitalia [3]. However, most patients who were diagnosed during infancy had ambiguous genitalia. Adolescent patients may present with a lack of puberty signs, leading to infertility in adulthood [15].

In our study, the second most common complaint was short stature. Heights seemed to be normal under the age of 2 years, but growth deceleration was found thereafter. Among patients older than 2 years, $62.9 \%$ presented short stature. Females seemed to be shorter than males were, though not significantly. The shortest girl was slightly taller than the previously reported shortest
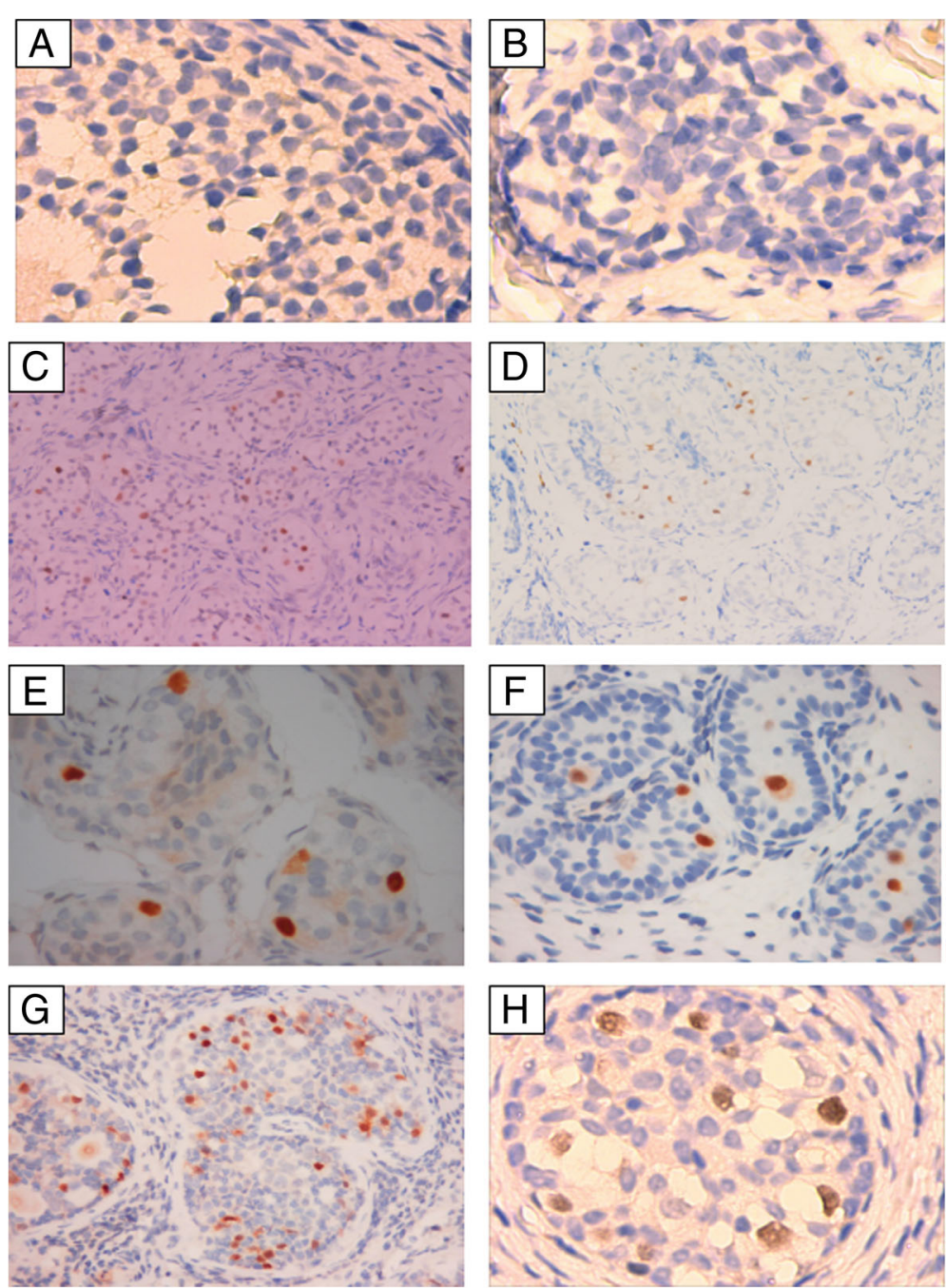

Fig. 2 Results of immunohistochemistry staining. $A$ and B (No. 21 and 31), negative for OCT3/4(× 400); C H (No. 2, 9,18, 26, 28 and 32), OCT3/4-positive staining (brown nuclear signal, A, B, E and $\mathrm{H} \times 400, \mathrm{C}$ and $\mathrm{D} \times 100, \mathrm{~F}$ and $\mathrm{G} \times 200$ ) 

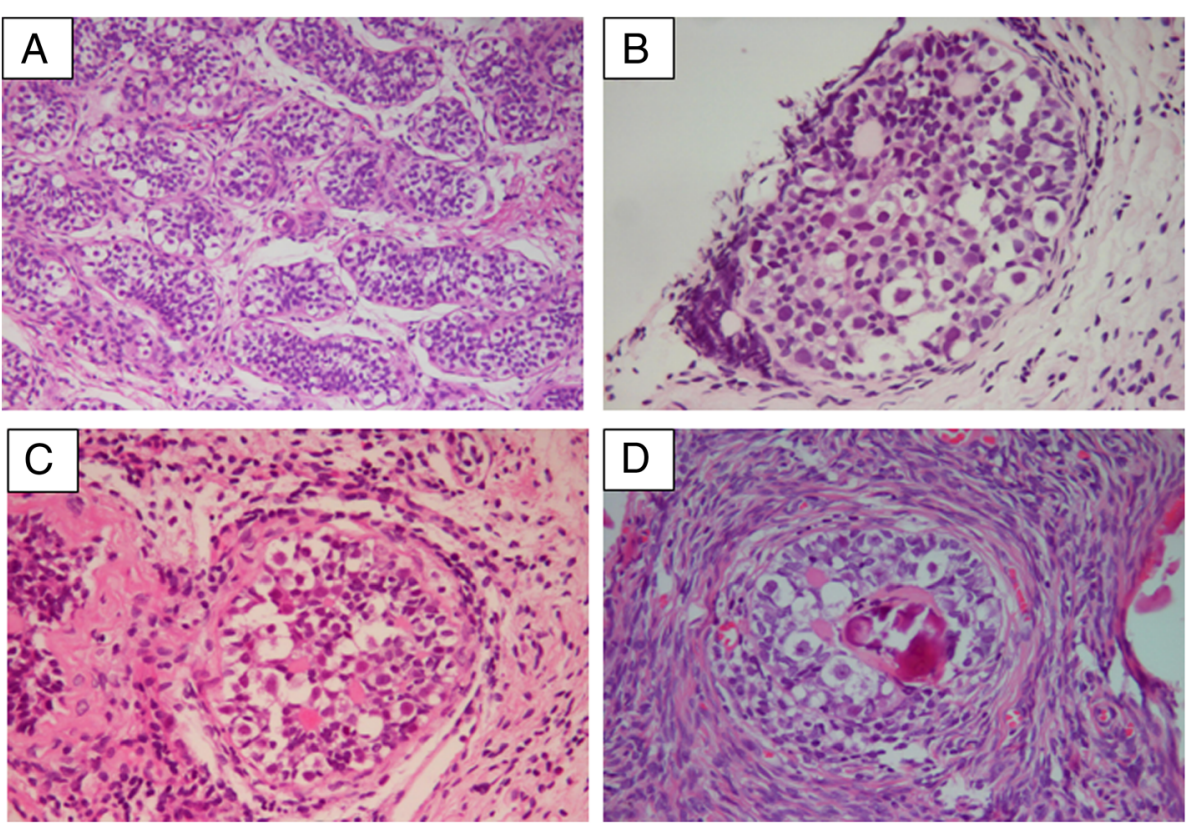

Fig. 3 Histological examination of gonadoblastoma. A, Normal testicular tissue (HE, $\times 100)$. B, C and D, gonadoblastoma (No. 24, 28 and 32, HE, $\times 100)$. The tumour cells are round or ovoid in shape and form nests that vary greatly in size. The nests are surrounded by fibrous connective tissue and have distinct borders, and calcification is present

Table 1 Summary of the literature review

\begin{tabular}{|c|c|c|c|c|c|c|c|}
\hline Year & Nation & Author & Cases & $\begin{array}{l}\text { NO. } \\
<18 Y\end{array}$ & $\begin{array}{l}\text { Other congenital } \\
\text { abnormalities }\end{array}$ & $\begin{array}{l}\text { Height } \\
<-2.0 \text { SDS }\end{array}$ & Gonadal histology \\
\hline 1990 & USA & Chang3 & 76 & / & 5 & / & OT2/3;PTL 1/3 \\
\hline 1999 & France & Telvi16 & 27 & 27 & 8 & 23 & CGD9/27,PGD7/27,MGD11/27 \\
\hline 2005 & Greece & Patsalis23 & 11 & / & 4 & / & CGD8/11,PGD1/11,MGD2/11 \\
\hline 2009 & USA & Kibar24 & 14 & 14 & 2 & / & CGD2/9, MGD7/9 \\
\hline 2010 & USA & Tosson17 & 16 & 16 & / & 8 & CGD3/15,PGD4/15, MGD9/15;GB2/15 \\
\hline 2012 & France & Martinerie18 & 20 & 20 & 9 & 14 & PGD1/18,MGD17/18 \\
\hline 2012 & Denmark & Lindhardt22 & 25 & 15 & 3 & / & CGD3/15,PGD5/15,MGD6/15,OT1/15 \\
\hline 2012 & Turkey & Ocal10 & 11 & 11 & / & / & CGD2/11,PGD4/11,MGD4/11,OT1/11 \\
\hline 2013 & UK & Farrugia25 & 31 & 31 & 15 & / & / \\
\hline 2014 & Brazil & Rosa15 & 14 & 12 & 4 & 6 & / \\
\hline 2015 & China & Chen19 & 7 & 7 & / & 7 & / \\
\hline 2015 & USA & Dendrinos 28 & 16 & 16 & / & / & GB4/16 \\
\hline 2016 & China & Jiang26 & 32 & / & 3 & / & CGD26/31,PGD5/31;GB4/Seminoma1(5/32) \\
\hline 2016 & China & Tam29 & 21 & 21 & / & / & CGD9/20,PGD11/20; CIS + GB 9/20 \\
\hline 2017 & China & Wu20 & 16 & 5 & 1 & 9 & $\mathrm{CGD} 2 / 2$ \\
\hline 2018 & Iran & Mohammadpour30 & 49 & / & / & / & PGD11/11 \\
\hline \multirow[t]{3}{*}{2018} & China & Huang21 & 19 & 19 & 5 & 15 & CGD11/18,PGD2/18,MGD5/18;GB2/18 \\
\hline & & & 405 & 214 & $59(59 / 285)$ & 82 & CGD75/191,PGD51/191, MGD61/191,OT4/191; \\
\hline & & & & & & $(82 / 119)$ & $\mathrm{GB}+\mathrm{CIS}+\mathrm{PLT}+$ Seminoma21/104 \\
\hline 2018 & China & Our study & 32 & 32 & $5(5 / 32)$ & $17(17 / 27)$ & CGD12/25,PGD3/25,MGD9/25,OT1/25; GB3/25 \\
\hline
\end{tabular}

$Y$ years; CGD complete gonadal dysgenesis; PGD partial gonadal dysgenesis; MGD mixed gonadal dysgenesis; OT ovotesticular tissue; / not specified; PTL precancerous testicular lesion; GB gonadoblastoma; CIS carcinoma-in situ 
female (-6.0 SDS vs -7.0 SDS) [16]. Similar to the data found in the literature review [15-21], more than half of the patients had short stature without growth hormone treatment [82/119 (68.9\%)]. Normal heights under age 2 years cannot predict normal stature later in life. Girls may need closer follow-up and more aggressive intervention. Notably, published evidence suggests that growth hormone treatment may be beneficial [17, 18, 22], with prophylactic gonadectomy being advocated prior to such treatment.

In our study, 40.6\% patients exhibited the phenotype of Turner syndrome and/or other congenital abnormalities, and they were all raised as females, whereas $15.6 \%$ of patients had other congenital abnormalities. A literature review of 285 cases with phenotype descriptions showed similar proportions of patients with additional congenital abnormalities of 59/285 (20.7\%) [3, 15, 16, 18, 20-26] (Table 1). Notably, compared to males, subjects assigned to the female gender showed a higher incidence of other congenital abnormalities [27]. Such patients should undergo a comprehensive assessment similar to that for Turner syndrome.

45,X/46,XY mosaicism used to be also called MGD or ovotesticular DSD. However, in our CGD and MGD were the most common gonadal pathogenic subtypes with proportions of 48 and 36\%, respectively. The other two subtypes accounted for less than $20 \%$ of subjects. The literature review revealed similar percentages $[3,10,16-$ $18,20-24,26,28-30]$ : CGD in $79 / 191$ patients $(41.4 \%)$, MGD in 61/191 (31.9\%), PGD in 51/191 (26.7\%) and OT in $4 / 191$ (2.1\%) patients (Table 1). More patients with a female phenotype or severe under virilisation phenotype tend to require a gonadal biopsy. This may be one possible reason for the higher proportion of patients with CGD in our study than that observed previously.

There have been a few reports on gonadal tumour risks in children. In our study, the total percent of gonadoblastoma and positive OCT3/4 was $21.7 \%$, similar to that found in the literature review, which was $20.2 \%$ (21/ 104) (Table 1). Immature germ cells are immunohistochemically characterized by increased TSPY expression and prolonged expression of embryonic germ cell markers, including OCT3/4 [31]. The combination of OCT3/4 and TSPY expression is considered valuable for the identification of malignant germ cells in dysgenetic gonads [29, 32-34]. Owing to the unavailability of other biomarkers such as TSPY, the risk of tumours in our study may have been underestimated. However, clinicians need to pay attention to the age-related change in OCT3/4, as OCT3/4-positive germ cells in patients under 2 years old indicates delayed maturation [35]. In our study, tumour risk seemed high even in palpable gonads (50\%), which was also higher than the values observed in Cools and Tam's reports [35.7\% (5/14) and
$25 \%$ (3/12), respectively] [29, 31]. Tumour risk in patients with a female phenotype was $13 \%$, which is less than the $52 \%$ risk in patients with an ambiguous phenotype $(0<$ EMS $<7.0)$ [32]. However, in our study, $27.3 \%$ of female phenotype patients had gonadoblastoma. Tam et al. [29] also reported that 6/11 (54.5\%) patients with female phenotype or raised as a female had gonadoblastoma or carcinoma-in situ. Therefore, the tumour risk may be high even in palpable gonads and in female patients. Gonadal biopsy is necessary without delay.

\section{Conclusions}

Patients with 45,X/46,XY mosaicism might have normal heights under the age 2 years. Growth decelerations after 2 years of age were common. Patients raised as females seemed to be shorter than males. CGD and MGD were the most common gonadal pathogenic subtypes. The tumour risk might be high, even in palpable gonads and female patients.

\section{Abbreviations \\ CGD: Complete gonadal dysgenesis; DSD: Disorder of sex development; EMS: External masculinization score; FSH: Follicle stimulating hormone; $\mathrm{GnRH}$ : Gonadotrophin-releasing hormone; hCG: human chorionic gonadotrophin; HPG: Hypothalamic-pituitary-gonadal; LH: Luteinizing hormone; MGD: Mixed gonadal dysgenesis; OCT3/4: Octamer binding transcription factor 3/4; OT: Ovotesticular tissue; PGD: Partial gonadal dysgenesis; PLAP: Placental alkaline phosphatase; SDS: Standard deviation score; TSPY: Testis-specific protein on the Y chromosome}

\section{Acknowledgements \\ Not applicable. \\ Funding \\ Not applicable. \\ Availability of data and materials \\ The datasets used and analysed during the current study are available from the corresponding author on reasonable request.}

\section{Authors' contributions}

ZS and LLP designed the study. JMS conducted the histology experiments. LLP, ZS, JMS, WHX, XL, LJZ and SLL had made contributions to the

acquisition, analysis, and interpretation of data. LLP wrote the manuscript; ZS and JMS oversaw the planning and execution of the data analysis, as well as reviewed and revised the manuscript. All authors read and approved the final manuscript.

\section{Ethics approval and consent to participate \\ This study was reviewed and approved by the Ethics Committee of Shenzhen Children's Hospital. We retrospectively reported the patient data without providing any individual details, images or videos.}

\section{Consent for publication}

All the authors have approved the manuscript and agree with submission to your esteemed journal.

Competing interests

The authors declare that they have no competing interests.

\section{Publisher's Note}

Springer Nature remains neutral with regard to jurisdictional claims in published maps and institutional affiliations. 
Received: 26 January 2019 Accepted: 24 April 2019

Published online: 06 May 2019

\section{References}

1. Hughes IA, Houk C, Ahmed SF, et al. Consensus statement on management of intersex disorders. J Pediatr Urol. 2006 Jun;2(3):148-62.

2. Houk CP, Lee PA. Consensus statement on terminology and management: disorders of sex development. Sex Dev. 2008:2(4-5):172-80.

3. Chang HJ, Clark RD, Bachman $H$. The phenotype of $45, X / 46, X Y$ mosaicism: an analysis of 92 prenatally diagnosed cases. Am J Hum Genet. 1990 Jan;46(1):156-67.

4. McGowan-Jordan J, Simons A, Schmid M, editors. An International System for Human Cytogenomic Nomenclature. Basel, Freiburg: Karger; 2016.

5. Hu YM, Jiang ZF. Zhu Fu tang practice of pediatrics. 7th ed. Beijing: People's Medical Publishing House; 2002. p. 23-38.

6. Marshall WA, Tanner JM. Variations in the pattern of pubertal changes in boys. Arch Dis Child. 1970;45:13-23.

7. Marshall WA, Tanner JM. Variations in the pattern of pubertal changes in girls. Arch Dis Child. 1969 Jun;44(235):291-303.

8. Ahmed SF, Khwaja O, Hughes IA. The role of a clinical score in the assessment of ambiguous genitalia. BJU Int. 2000 Jan;85(1):120-4.

9. Welt CK. Primary ovarian insufficiency: a more accurate term for premature ovarian failure. Clin Endocrinol. 2008 Apr;68(4):499-509.

10. Ocal G, Berberoğlu M, Sıklar Z, et al. The clinical and genetic heterogeneity of mixed gonadal dysgenesis: does "disorders of sexualdevelopment (DSD)" classification based on new Chicago consensus cover all sex chromosome DSD? Eur J Pediatr. 2012 Oct;171(10):1497-502.

11. Slowikowska-Hilczer J, Szarras-Czapnik M, Wolski JK, et al. The risk of neoplasm associated with dysgenetic testes in prepubertal and pubertal/ adult patients. Folia Histochem Cytobiol. 2015;53(3):218-26.

12. Moch H, Humphrey PA, Ulbright TM, Reuter VE. WHO classification of Tumours of the urinary system and male genital organs, vol. 8. 4th ed; 2016

13. Colindres JV, Axelrad M, McCullough L, et al. Evidence-Based Management of Patients with 45,X/46,XY Gonadal Dysgenesis and Male Sex Assignment: from Infancy to Adulthood. Pediatr Endocrinol Rev. 2016 Mar;13(3):585-601.

14. Robinson WP, Binkert F, Bernasconi F, et al. Molecular studies of chromosomal mosaicism: relative frequency of chromosome gain or loss and possible role of cell selection. Am J Hum Genet. 1995 Feb;56(2):444-51.

15. Rosa RF, D'Ecclesiis WF, Dibbi RP, et al. 45,X/46,XY mosaicism: report on 14 patients from a Brazilian hospital. A retrospective study. Sao Paulo Med J. 2014 Dec;132(6):332-8.

16. Telvi L, Lebbar A, Del Pino O, et al. 45,X/46, XY mosaicism: report of 27 cases. Pediatrics. 1999 Aug;104(2 Pt 1):304-8.

17. Tosson H, Rose SR, Gartner LA. Children with 45,X/46,XY karyotype from birth to adult height. Hom Res Paediatr. 2010;74(3):190-200.

18. Martinerie $L$, Morel $Y$, Gay CL, et al. Impaired puberty, fertility, and final stature in45,X/46, XY mixed gonadal dysgenetic patients raised as boys. Eur J Endocrinol. 2012 Apr;166(4):687-94.

19. Chen G, Dou J, Yang G, et al. The diagnosis, treatment and following up of 7 patients with $45, \mathrm{X} / 46, \mathrm{XY}$ mixed gonadal dysgenesis. Zhonghua Nei Ke Za Zhi. 2015;54(11):954-8.

20. Wu Q, Wang $C$, Shi $H$, et al. The clinical manifestation and genetic evaluation in patients with 45,X/46,XY mosaicism. Sex Dev. 2017;11(2):64-9.

21. Huang $Y C$, Lee $C T, W u M Z$, et al. The spectrum of $45, X / 46, X Y$ mosaicism in Taiwanese children: the experience of a single center. J Formos Med Assoc. 2019 Jan;118(1 Pt 3):450-6.

22. Lindhardt Johansen $M$, Hagen $C P$, Rajpert-De Meyts $E$, et al. 45,X/46,XY mosaicism: phenotypic characteristics, growth, and reproductive function: are trospective longitudinal study. J Clin Endocrinol Metab. 2012 Aug;97(8):E1540-9

23. Patsalis PC, Skordis N, Sismani $C$, et al. Identification of high frequency of $Y$ chromosome deletions in patients with sex chromosome mosaicism and correlation with the clinical phenotype and Y-chromosome instability. Am J Med Genet A. 2005 Jun 1;135(2):145-9.

24. Kibar $Y$, Frimberger $D$, Kropp BP, et al. Accuracy of perinatal diagnosis of $45, X / 46, X Y$ mosaicism and electronic consultation of affected parents. J Pediatr Urol. 2009 Aug;5(4):274-8

25. Farrugia MK, Sebire NJ, Achermann JC, et al. Clinical and gonadal features and early surgical management of 45,X/46,XY and 45,X/47,XYY chromosomal mosaicism presenting with genital anomalies. J Pediatr Urol. 2013;9(2):139-44
26. Jiang JF, Tian QJ, Xue W, et al. Clinical features of 32 patients with XO/ XY gonadal dysgenesis. Zhongguo Yi Xue Ke Xue Yuan Xue Bao. 2016 Aug;38(4):411-4.

27. Tosson H, Rose $S R$, Gartner LA. Description of children with $45, X / 46, X Y$ karyotype. Eur J Pediatr. 2012 Mar;171(3):521-9.

28. Dendrinos ML, Smorgick N, Marsh CA, et al. Occurrence of Gonadoblastoma in patients with 45,X/46,XY mosaicism. J Pediatr Adolesc Gynecol. 2015 Jun;28(3):192-5.

29. Tam $Y H$, Wong $Y S$, Pang KK, et al. Tumor risk of children with $45, X / 46, X Y$ gonadal dysgenesis in relation to their clinical presentations: further insights into the gonadal management. J Pediatr Surg. 2016:51(9):1462-6.

30. Mohammadpour Lashkari F, Sadighi Gilani MA, Ghaheri A, et al. Clinical aspects of 49 infertile males with 45,X/46,XY mosaicism karyotype: a case series. Andrologia. 2018 Jun;50(5):e13009.

31. Cools M, Pleskacova J, Stoop H, et al. Gonadal pathology and tumor risk in relation to clinical characteristics in patients with 45,X/46,XY mosaicism. J Clin Endocrinol Metab. 2011 Jul;96(7):E1171-80.

32. Kersemaekers AM, Honecke F, Stoop M, et al. Identification of germ cells at risk for neoplastic transformation in gonadoblastoma: an immunohistochemical study for OCT3/4 and TSPY. Hum Pathol. 2005 May;36(5):512-21.

33. Palma I, Garibay N, Pena-Yolanda R, et al. Utility of OCT3/4,TSPY and $\beta$-catenin as biological markers for gonadoblastoma formation and malignant germ cell tumor development in dysgenetic gonads. Dis Markers. 2013;34:419-24.

34. Oosterhuis JW, Stoop H, Dohle G, et al. A pathologist's view on the testis biopsy. Int J Androl. 2011 Aug:34(4 Pt 2):e14-9.

35. Thorup J, Clasen-Linde E, Cortes D. Positive Oct-3/4 and D2-40 Immunohistochemical expression in germ cells and suspected histology pattern of IntratubularGerm cell neoplasia in boys with cryptorchidism vanish after the age of 2 years. Eur J Pediatr Surg. 2017 Aug;27(4):313-8.

Ready to submit your research? Choose BMC and benefit from:

- fast, convenient online submission

- thorough peer review by experienced researchers in your field

- rapid publication on acceptance

- support for research data, including large and complex data types

- gold Open Access which fosters wider collaboration and increased citations

- maximum visibility for your research: over $100 \mathrm{M}$ website views per year

At $\mathrm{BMC}$, research is always in progress.

Learn more biomedcentral.com/submissions 